\title{
AJARAN AGAMA HINDU \\ DALAM PENINGKATAN KERUKUNAN RUMAH TANGGA MENUJU KEHARMONISAN HIDUP
}

\author{
Oleh \\ Ni Wayan Gateri \\ Tenaga Pendidik pada STAHN Tampung Penyang Palangkaraya
}

\begin{abstract}
Harmony is a dream for every household that are nurtured with love, compassion, and sincerity. In improving household harmony a grounding Hindu religion as guidance is needed. Household harmony is a state of peace, good, friendly, united hearts, agreement that occur in a family life with overcome differences of opinion and differences of understanding. The increase in household harmony creates a peaceful family circumstances that shows happy, life without violence, as well as inner and outer prosperous which are based on realizing the teachings of truth and religion.
\end{abstract}

Keywords: Teachings of Hinduism, Improvement, Household Harmony, Harmony Of Life.

\section{PENDAHULUAN}

Makna keharmonisan atau kerukunan rumah tangga itu sendiri jika dipandang dari pandangan agama Hindu, yang utama bahwa yang namanya keharmonisan/kerukunan itu merupakan kebutuhan pokok bagi setiap umat manusia. Tidak saja keharmonisan/kerukunan tersebut sebagai dambaan bagi rumah tangga, maka kerukunan tersebut juga harapan dalam masyarakat, dalam negara, dalam kelembagaan formal maupun nonformal, serta bagi setiap insan yang hidup di dunia ini. Kata kerukunan lebih banyak dan nyata sering dirangkaikan dengan kata rumah tangga. Tetapi dalam kehidupan beragamapun bahwa kata kerukunan juga sudah menjadi bagian yang tidak terpisahkan. Oleh karena kerukunan umat beragama, baik secara intern umat beragama, antar umat beragama, dan kerukunan antar umat beragama dengan pemerintah merupakan program utama yang dilakukan oleh pemerintah melalui Kementerian Agama Republik Indonesia.

Ajaran Tat Twam Asi adalah ajaran moral yang bernafaskan ajaran agama Hindu. Wujud nyata/riil dari ajaran ini dapat kita cermati dalam kehidupan dan prilaku keseharian dari umat manusia yang bersangkutan. Manusia dalam hidupnya memiliki berbagai macam kebutuhan hidup yang dimotifasi oleh keinginan (kama) manusia yang bersangkutan. Sebelum manusia sebagai makhluk hidup itu banyak jenis, sifat, dan ragamnya, seperti manusia sebagai makhluk, individu, sosial, religius, ekonomis, budaya, dan yang lainnya. Semua itu harus dapat dipenuhi oleh manusia secara menyeluruh dan bersamaan tanpa memperhitungkan situasi dan kondisinya serta keterbatasan yang dimilikinya, betapa susah yang dirasakan oleh individu yang bersangkutan. Di sinilah manusia perlu mengenal dan melaksanakan rasa kebersamaan, sehingga seberapa berat masalah 
yang dihadapinya akan terasa ringan. Dengan memahami dan mengamalkan ajaran Tat Twam Asi, manusia akan dapat merasakan berat dan ringan hidup dan kehidupan ini. Semua diantara kita ini tahu bahwa berat dan ringan (Rwabhineda) itu ada dan selalu berdampingan adanya, serta sulit dipisahkan keberadaanya. Demikian adanya maka dalam berumah tangga kita hendaknya selalu sering tolong menolong, saling menghargai, saling mengasihi dan senasib sepenanggungan.

Kata 'rukun' artinya 1. baik dan damai; tidak bertengkar (tentang pertalian persahabatan dan sebagainya; 2 . bersatu hati; bersepakat. Sedangkan 'kerukunan' artinya 1. perihal hidup rukun, mendamaikan; 2. rasa rukun; kesepakatan (Tim Penyusun, 1994:850). Istilah 'rumah tangga' diartikan 1 . sesuatu yang berkenaan dengan urusan kehidupan di rumah (seperti hal belanja rumah dan sebagainya); 2 . berkenaan dengan keluarga (Tim Penyusun, 1994:851). Jadi dapat ditegaskan bahwa 'kerukunan rumah tangga' yang dimaksudkan adalah suatu keadaan penuh damai, baik, bersahabat, bersatu hati, bersepakat yang terjadi dalam kehidupan berumah tangga atau hidup berkeluarga, sehingga tidak terjadi kondisi yang tidak harmonis ataupun perbedaan pendapat/perbedaan pemahaman dalam keluarga. Juga bahwa 'kerukunan rumah tangga' adalah keadaan keluarga yang damai (santih), bahagia (anadam), hidup tanpa kekerasan (janman na himsa), serta sejahtra lahir batin (hita sakala ca niskala) yang berlandaskan pada ajaran kebenaran (dharma).

Terkait dengan tindakan kekerasan dalam rumah tangga, selanjutnya dapat dibaca Undang-Undang Republik Indonesia Nomor 23 tahun 2004 tentang 'Penghapusan Kekerasan Dalam Rumah Tangga'. UURI nomor 23 tahun 2004 memberikan landasan hukum untuk penghapusan dan pencegahan tindak kekerasan, di samping perlindungan korban, serta penindakan terhadap pelaku, dengan upaya tetap menjaga keutuhan dan keharmonisan rumah tangga. Tujuannya adalah :a) mencegah segala bentuk kekerasan dalam rumah tangga, b) melindungi korban kekerasan dalam rumah tangga, c) menindak pelaku kekerasan dalam rumah tangga, dan d) memelihara keutuhan rumah tangga yang harmonis dan sejahtera (Biwa, t.t.:2-3). Makna UURI 23 tahun 2004 adalah menempatkan norma baru yakni : pertama, tidak ada toleransi terhadap kekerasan dalam ruma tangga, kedua, kekerasan dalam rumah tangga bukan urusan pribadi tetapi urusan masyarakat dan pemerintah dan kewajiban kita semua untuk menghapusnya. Katakan 'TIDAK' pada kekerasan dalam rumah tangga (Biwa,t.t.:3). Produk hukum itu perlu juga dipahami dengan baik, selain dapat memahaminya dalam ajaran suci agama Hindu.

Dengan demikian bahwa 'kerukunan rumah tangga' adalah modal utama bagi kerukunan hidup yang lainnya, karena kerukunan rumah tangga sebagai kunci dan kendali kerukunan yang berada di akar rumput, sehingga jika hal ini bisa berhasil, diyakini pula bahwa kerukunan pada komponen yang lainnya bisa sukses pula. Sebagai misal, seorang pegawai yang keadaan rumah tangganya cekcok, benyut atau mebuut-buutan, maka kinerja pegawai tersebut di tempat tugasnya pasti akan berpengaruh dan tidak terkonsentrasi dengan baik. Juga jika ada siswa yang tidak diberikan keperluan keuangan dan sarana belajarnya dengan baik oleh orang tuanya, maka diyakini akan menimbulkan masalah dalam belajar di sekolahnya, bisa saja tidak naik kelas, bisa saja menjadi malas ke sekolah, atau bisa menjadi anak bandel, pembangkang atau suka mencuri di sekolah, misalnya. Maka dari itu, bahwa kerukunan rumah tangga sebagai kunci sukses pula dalam hal kesuksesan kehidupan lainnya, baik dalam hal profesi, karier, studi, usaha, bisnis, tugas serta yang lainnya. Nah bagaimana penerapan ajaran tat twam asi dalam meningkatkan 
kerukunan rumah tangga tersebut sehingga terwujudnya keharmonisan masyarakat Hindu. Mari simak uraian sekilas berikut ini.

\section{PEMBAHASAN}

\subsection{Sekilas Ajaran Tat Twam Asi}

Tat Twam Asi adalah ajaran tata Susila dalam agama Hindu. Susila adalah istilah lain dari Ethika dan Moral, merupakan dua buah kata dalam kehidupan yang dipergunakan silih berganti untuk maksusd yang sama. Kata Susila terdiri dari kata " $\mathrm{Su}$ " yang berarti baik dan "Sila" berarti segala kebiasaan atau tata laku. Susila berarti perbuatan yang baik atau tata laku yang baik. Jadi Susila adalah peraturan tingkah laku yang baik dan mulia yang harus menjadi pedoman hidup manusia.

Tujuan tata Susila adalah untuk membina hubungan yang selaras atau hubungan yang rukun antara seseorang dengan makhluk yang hidup di alam sekitarnyarnya. Telah menjadi kenyataan bahwa hubungang selaras atau rukun antara seseorang dengan makhluk sesamanya, antara anggota-anggota suatu masyarakat, suatu bangsa, menyebabkan hidup aman dan sentosa. Disamping meningkatkan moral, sekaligus merupakan nilai budaya yang dapat meningkatkan derajat manusia dari yang rendah ketingkat yang lebih tinggi. Salah satu prinsip dasar dalam ajaran susila itu menurut agama Hindu adalah dalam rangka menyeberangkan Sang Hyang Atma agar dapat mencapai moksa. Dengan demikian Susila dalam hal ini Susila Hindu Dharma adalah bagian yang sangat penting dalam agama Hindu. Oleh karena itu penganut agama Hindu sudah semestinya harus mengenal dan memahami ajaran Susila disamping Filsafat dan Upacara. Setelah mengenal dan memahaminya tentu melaksanakan atau mengamalkannya.

Ajaran Susila Hindu Dharma berlandaskan Filsafat diantaranya adalah Tat Twam Asi. Kata Tat Twam Asi berasal dari bahasa Sanskerta yaitu "Tat" berarti itu, "Twam" berarti kamu dan "Asi" berarti adalah. Jadi Tat Twam Asi berarti itu atau dia adalah kamu juga. Maksud yang terkandung dalam ajaran Tat Twam Asi ini "ia adalah kamu, saya adalah kamu, dan semua makhluk adalah sama" sehingga bila kita menolong orang lain berarti juga menolong diri kita sendiri. Didalam filsafat Hindu dijelaskan bahwa Tat Twam Asi adalah ajaran kesusilaan yang tanpa batas, yang identik dengan "prikemanusiaan" dalam Pancasila. Konsep sila prikemanusiaan dalam Pancasila, bila kita cermati sungguh-sungguh adalah merupakan realisasi ajaran Tat Twam Asi yang terdapat dalam kitab suci Weda.

Tat Twam Asi adalah ajaran moral yang bernafaskan agama Hindu. Wujud nyata dari ajaran ini dapat kita cermati dalam kehidupan dan prilaku keseharian dari umat manusia yang bersangkutan. Manusia dalam hidupnya memiliki berbagai macam kebutuhan hidupyang dimotifasi oleh keinginan manusia yang bersangkutan. Sebutan manusia sebagai makhluk hidup itu banyak jenis, sifat dan ragamnya, seperti manusia sebagai makhluk individu, social, religius, ekonomis, budaya, dan yang lainnya. Semua itu harus dapat dipenuhi oleh manusia secara menyeluruh dan bersamaan tanpa memperhitungkan situasi dankondisi serta keterbatasan yang dimilikinya. Disinilah manusia perlu mengenal dan melaksanakan rasa kebersamaan, sehingga seberapa berat masalah yang dihadapi akan terasa ringan. Dengan memahami dan mengamalkan ajaran Tat Twam Asi, manusia akan dapat merasakan berat dan ringan gan dalam hidup dan kehidupan ini se berdampingan adanya dan sulit dipisahkan keberadaannya. Dengan demikian maka dalam hidup ini kita hendaknya selalu saling tolong menolong, merasa senasib dan sepenanggungan.

Prilaku sebagai implementasi ajaran Tat Twam Asi jika diperinci ada tiga bentuk antara lain: 


\section{1) Hormat dan Kasih kepada Keluarga}

- Hormat kepada Ibu Bapak

Didalam keluarga ada orang tua dan keluarga. Kepada semua itulah harus hidup saling menghormati, sehingga tidak ada permusuhan satu sama lain. Semua pihak harus menjalankan kesusilaan yang dilandasi dengan Tat Twam Asi. Hormat kepada orang tua itu seperti mendengarkan nasehatnya, saling menyayangi dan sebagainya.

- Cinta kepada saudara.

Bangunlah sikap Tat Twam Asi diantara saudara. Ini penting supaya tercipta suasana damai diantara saudara. Bila ada masalah supaya diselesaikan dengan musyawarah, masing-masing pihak harus mampu mengendalikan diri, tidak terbius oleh kama negatif seperti Sad Ripu dan sebagainya. Waspadai pihak ketiga yang mencoba menggoda kerukunan bersaudara.

\section{2) Hormat kepada Guru dan Teman} sekelas.

- Hormat kepada Guru.

Murid atau siswa harus hormat kepada orang tua (Guru Rupaka) juga kepada Guru Pengajian, karena merekalah yang mendidiknya agar dapat berkembang menjadi dewasa dalam berpikir, mengembangkan intelektualnya, memiliki rasa tanggung jawab, bermoral serta dapat berguna bagi nusa dan bangsa. Betapa hutang budhi yang dimiliki siswa yang tak mungkin bisa dibayar. Jasa Guru Pengajian amatlah besar, oleh karena itu rasa hormat kepada Guru sampai kapanpun perlu dipupuk. Tak dapat dibayangkan bagaimana jadinya seseorang jika tak berpendidikan. Oleh karena itu patuhi nasehat guru, rajin belajar dan jangan lupa segala bimbingannya.

- Cinta kasih kepada teman.

Seseorang tidak bisa huidup dalam kesendiriannya, ia butuh teman dari seseorang. Untuk itu seseorang perlu mencari teman. Dengan berteman seseorang akan dapat menjadi orang. Ada ungkapan bahwa teman yang baik adalah teman yang ingat pada saat dirinya mengalami kesusahan. Pada saat bahagia datang atau tidak, tak menjadi masalah. Tapi saat menderita teman itu perlu ditengok. Bila perlu dibantu. Kapan lagi membantu kalau tidak saat kesusahan. Itulah tanda persahabatan yang baik. Oleh karena itu pupuklah persahabatan itu dengan baik, hindari permusuhan, dengan saling mencintai, saling mengasihi, saling menolong, saling tenggang rasa persahabatan menjadi kekal. Persahabatan yang kekal akan banyak memberi manfaat dalam kehidupan ini.

3) Cinta Kasih kepada Lingkungan (Binatang, Tumbuh-tumbuhan, Alam sekitar)

Disamping lingkungan harus bersih, juga harus menyayangi binatang piaraan dengan memberi makan dan minum. Lingkungan harus bersih baik di rumah maupun di sekolah karena sangat berpengaruh terhadap kesehatan kita. Tumbuh-tumbuhan mesti ditata agar dapat membuat keindahan dan kesejukan. Perhatikan kelestarian lingkungan, karena lingkungan yang lestari dapat memberikan keindahan. Cintailah lingkungan karena banyak memberi manfaat kepada diri sendiri.

Bila ajaran Tat Twam Asi dapat diimplementasikan dalam kehidupan sehari-hari kepada umat manusia secara 
menyeluruh dan sungguh-sungguh, dalam sifat dan prilaku kita maka kehidupan ini akan menjadi harmonis. Satu dengan yang lainnya diantara kita dapat hidup saling menghormati, mengasihi dan damai.

\subsection{Ajaran Agama Hindu sebagai Ajaran}

Peningkatan Kerukunan Rumah Tangga Menuju Keharmonisan Hidup

Berbicara mengenai kerukunan rumah tangga menurut pandangan agama Hindu, maka akan dipaparkan beberapa konsep kerukunan sesuai sumber pustaka suci Hindu, antara lain : kerukunan rumah tangga dalam Weda, Bhagawadgita, Sarasamuscaya, Slokantara, dan dalam pustaka suci Manawadharmasastra.

\subsubsection{Kerukunan Rumah Tangga Dalam Weda}

Dalam pustaka suci Yajurveda XII.58 dan Atharvaveda XIV.2.43., III.30.3, III.30.1, VI.74.2 (Titib,1996:406-409) dinyatakan bahwa pasangan (suami istri) seharusnya memiliki keserasian pemikiran, senantiasa tetap riang gembira, hendaknyalah ada keserasian di keluarga, seharusnya selalu ada keserasian di dalam keluarga, dan kerukunan di dalam keluarga. Simak kutipannya berikut ini.

Sam vâm manâmsi sam vratâ

Sam u cittâni-âkaram

Aku harmoniskan pikiran, tindakan dan hati pasangan (suami-isteri) ini.

\section{Hasâmudau mahasâ modamânau}

Wahai pasangan suami istri, berenang hatilah dengan kegiatan usahamu dan jalanilah hidup yang riang gembira.

\section{Mâ bhrâtâ bhrâtaram dviksat}

Mâ svasâram uta svasâ

Samyansah savratâ bhutvâ

Vâcam vadata bhadrayâ

Saudara laki seharusnya tidak cemburu (irihati) kepada saudara lakinya dan sama juga saudara perempuan janganlah irihati kepada saudara perempuannya. Dengan demikian yang sama dan melakukan tugastugas yang sama, anda seharusnya bercakap-cakap dengan mesra.

\section{Sahrdayam sâmmanasyam \\ Avidvesam krnomi vah Anyo-anyam abhi haryata Vatsam jâtam iva-aghnyâ} Wahai para pria, Aku memberikan kepadamu sifat-sifat tulus ikhlas, kerukunan (keserasian) dan merasakan berteman tanpa suatu kebencian (permusuhan). Seperti halnya induk sapi mencintai anaknya yang baru lahir, begitulah anda seharusnya mencintai teman-temanmu.

\section{Samjnapanam vo manasah \\ Atho samjnapanam hrdah \\ Atho bhagasya yat srântam \\ Tena samjnapayâmi vah.}

Hendaknyalah terdapat keserasian pikiranmu dan hatimu. Kami menyerasikan (mengharmoniskan) anda dengan kemasyuran Kuvera (dewanya) kekayaan.

Bila disimak dengan mendalam beberapa kutipan di atas, bahwa kehidupan keluarga yang berkaitan dengan kerukunan rumah tangga sangat banyak diajarkan dalam pustaka suci Weda. Beberapa ajaran suci di atas telah memberikan rambu-rambu bagi kehidupan keluarga yang tentram, harmonis, dan rukun.

\subsubsection{Kerukunan Rumah Tangga Dalam Bhagawadgita}

Dalam pustaka suci Bhagawadgita nava adhyaya sloka 25, 26, 27, 29, 31, dan 34 (Pudja, 2004:239-244) dinyatakan betapa pentingnyainsan Hindu yang budiman termasuk sedharma dalam ikatan keluarga untuk melakukan pemujaan kepada deva, memuja leluhur, mencintai alam, memiliki pribadi ikhlas, sifat suci/mulia, selalu berkarma baik, 
berdisiplin, berbakti, gemar melakukan pengabdian kepada Tuhan dan sesama, menjadi insan dalam kebenaran, kedamaian, memiliki pikiran dan dapat mengendalikan diri, maka semuanya itu menjadi dasar dalam keharmonisan dalam keluarga. Simak makna kutipan slokanya berikut ini.

Yânti deva-vratâ devân

Pitrn yânti pitr-vratâh,

Bhutâni yânti bhutyejyâ

Yânti mad-yâjino 'pi mâm.

Yang memuja devatâ pergi kepada para devat $\hat{a}$, kepada leluhur perginya yang memuja leluhur mereka, dan kepada roh alam perginya yang memuja roh alam, tetapi mereka yang memuja-Ku, datang kepada$\mathrm{Ku}$.

Patram puspam phalam toyam

Yo me bhaktyâ prayacchati,

Tad aham bhakty-upahrtam

Asnâmi prayatâtymanah.

Siapapun yang dengan sujud bhakti kepada-Ku mempersembahkan sehelai daun, sekuntum bunga, sebiji buah-buahan, seteguk air, Aku terima sebagai bhakti persembahan dari orang yang berhati suci.

Yat karosi yad asnâsi

Yaj juhosi dadâsi yat,

Yat tapasyai kaunteya

Tat kurusva mad arpanam.

Apapun yang engkau kerjakan, engkau makan, engkau persembahkan, engkau dermakan dan disiplin diri apapun yang engkau laksanakan, lakukanlah, wahai Arjuna sebagai bhakti pada-Ku.

Samo 'ham sarva-bhutesu

Na me dvesyo 'sti na priyah,

Ye bhajanti tu mâm bhaktyâ

Mayi te tesu câpy aham.

Aku adalah sama bagi semua makhluk, bagi-Ku tiada yang terbenci dan terkasihi; tetapi mereka yang berbhakti padaku dengan penuh pengabdian, mereka ada padaku dan Aku ada pada mereka.

Ksipram bhavati dharmâtmâ

Sasvac-chântim nigacchati,

Kaunteya pratijânihi

Na me bhaktah pranasyati.

Dengan segera ia menjadi orang benar dan mencapai kedamaian yang kekal abadi; ketahuilah, wahai Arjuna, para pemuja-Ku pasti tak akan termusnahkan.

Man-manâ bhava mad-bhakto

Mad-yâji mâm namaskuru,

Mâm evaisyai yuktvaivam,

Âtmânam mat-parâyanah.

Pusatkan pikiranmu, pada-Ku, berbhakti pada-Ku, bersujud pada-Ku, sembahlah Aku dan setelah kau mengendalikan dirimu dengan Aku jadi tujuanmu tertinggi, engkau akan tiba pada-Ku.

Adapun pesan-pesan yang bisa dijadikan pedoman dalam membina keluarga yang harmonis dan rukun sesuai kutipan sloka suci di atas, seperti berikut ini.

1) Setiap anggota keluarga hendaknya selalu memuja Hyang Widhi, devata, leluhur, dan menghormati sesama beserta lingkungan sekitar;

2) Setiap anggota keluarga rajin melakukan persembahan dengan hati suci, dengan sarana berupa daun, bunga, buah, air, maupun yang lainnya yang dimiliki, maka Tuhan pasti menerima dan menganugerahi kerahayuan keluarga;

3) Setiap anggota keluarga hendaknya ulet bekerja, menikmati hasil kerja dengan suka cita, gemar berderma, hidup dengan disiplin, serta selalu berbakti dengan semuanya;

4) Setiap anggota keluarga dapat berlaku adil tanpa pilih kasih, tidak ada yang 
dibenci sekali, tidak ada yang terlalu dikasihi, gemar mengabdi, dan berbakti terhadap semuanya;

5) Setiap anggota keluarga dapat menjadi teladan dalam kebenaran, menciptakan kedamaian dan kerukunan yang abadi dalam keluarga;

6) Setiap anggota keluarga dapat melakukan sesuatu dengan penuh konsentrasi, gemar memuja, berbakti, bersujud, menyembah, serta dapat mengendalikan diri dengan baik sehingga tujuan yang utama dalam keluarga bisa terwujud, baik secara sakala maupun niskala.

Demikian pesan suci dalam pustaka Bhagavadgita seperti yang telah dipaparkan di atas, yang harapannya adalah agar terwujudnya keluarga yang sejahtera, bahagia, tenteram, damai, rukun, dan harmonis secara langgeng, bagi semua anggota keluarga dalam kehidupan berumah tangga.

\subsubsection{Kerukunan Rumah Tangga Dalam Sarasamuscaya}

Konsep kerukunan rumah tangga bila dibaca dalam pustaka suci Sarasamuscaya, maka banyak ajaran yang bisa dijadikan pedoman hidup dalam membina rumah tangga, yang harapannya agar kehidupan berkeluarga menjadi tentram, rukun, dan damai. Sebagaimana diketahui bahwa dalam pustaka Sarasamuscaya isinya sarat dengan ajaran yang berisi tuntunan hidup atau susila yang bermanfaat bagi umat manusia termasuk dalam kehidupan berkeluarga.

Beberapa ajaran suci yang patut dijadikan tuntunan dalam berperilaku dalam keluarga, seperti : pentingnya kebenaran (dharma), ada empat tata kehidupan mulia bagi masyarakat Hindu (catur warna), tiga tatanan perilaku yang wajib dimuliakan/disucikan (tri kaya parisudha), yaitu hendaknya berpikiran mulia/ suci (manacika parisudha), hendaknya memperhatikan perilaku yang mampu menasihati diri, yakni jangan irihati (irsya atau matsarya), berlaku sabar (ksama), jangan marah (akrodha), jangan berlaku tanpa kepercayaan (nastika), kendalikan perkataan (wak), pertahankan kebenaran (satya), jangan suka menyakiti/membunuh (ahimsa), dilarang mencuri (asteya), dan dilarang memperkosa gadis/wanita lain (paradara).

Kemudian hendaknya dapat berperilaku baik (susila), adanya toleransi anak terhadap orang tua (ramarena atau gurususrusa), dapat mengendalikan diri secara internal dan eksternal (yama niyama brata), carilah kekayaan berlandaskan kebenaran (dharma artha), ciptakan kebahagiaan (sukha), lakukan perjalanan suci ke pura (tirthayatra), entaskan kemiskinan (daridra), lakukan pergaulan sehat (subhasamsarga), bergaullah dengan orang baik (sadhu), jauhi pergaulan dengan orang jahat (papabudhi), jangan berlaku bodoh (punggung), berlaku dalam kestabilan dalan cinta dan kebencian (ragadwesa), jangan terlalu ketergantungan (tresna), dan tumbuhkan kemandirian (swadharma), dan ciptakan kebebasan hidup lahir batin (moksa).

Selanjutnya dapat pula disimak makna kutipan sloka dalam pustaka Sarasamuscaya terutama dalam sloka 152, 153, 154, 156, dan 158 (Kadjeng, dkk, 2000:80-82), berikut ini.

Duhkhine bandhuvargaya suhrde sansritaya ca,

Ya nabhidruhyata vrttih sa krpatigariyasi.

Apan ikang ulah manulung ring kadang warga, katekan lara prihati, yaning mitra kuneng, an ring mamarasraya, ya ika krpa ngaranya, wekasning inuttama $i k a$.

Karena perbuatan menolong kepada sanak keluarga, yang tertimpa penyakit serta prihatin atau kepada sahabat yang lagi mencari perlindungan, mereka itu adalah sama dengan orang miskin; pertolongan kepada mereka harus diutamakan. 
Paradara na gantavyah sarvavarnesu karhicit,

$\mathrm{Na}$ hidrsamanayusyam yathanyastrinisevanam.

Ikang kaparadaran, sarwadayani tan ulahakena ika haywa angulahaken asing amuhara alpayusa.

Menggoda/memperkosa wanita, segala usaha curang jangan dilakukan, pun jangan melakukan segala sesuatunya yang berakibat umur pendek.

Tat prajnena vinitena jnanavijnanavedina,

Nayuskamena sevyah syurmanasapi parasriyah.

Ya ta matangnya, sang prajna, sang susila, sang wruh ring parijnana, sang ahyun dirghayusa, tar lamba-lamban juga sira, mangenangenang kaparadaran.

Maka itulah sebabnya, orang yang arif, orang yang berkesusilaan, orang yang berilmu pengetahuan sempurna, orang yang berkehendak ingin berusia panjang, tidak sekali-kali memikirkan untuk memperkosa isteri orang.

Tasmad vakkayacittaistu nacaredasubham narah,

Subhasubham hyacarati tasya tasyanute phalam.

Matangnyan nihan kadayakenaning wwang, tan wak, kaya, manah, kawarjana, makolahang asubhakarma, apan ikang wwang mulahaken ikang hayu, hayu tinemunya, yapwan hala pinakolahnya, hala tinemunya.

Oleh karenanya, inilah harus diusahakan orang, jangan dibiarkan kata-kata laksana dan pikiran melakukan perbuatan buruk, karena orang yang melakukan sesuatu yang baik, kebaikanlah diperolenya; jika kejahatan merupakan perbuatannya, celaka yang ditemukan olehnya.
Dharmah satyam tatha vrttam balam sriscaiva pancamah,

Niscayena maharaja sada nastyatra sansayah.

Apan ikang dharma, satya, maryada yukti, kasaktin, sri, kinaniscayan ika, sila hetunya hana.

Karena kebajikan, kebenaran, pelaksanaan cara hidup yang layak (sopan santun), kesaktian, kebahagiaan, dan keteguhan itu, sila yang menyebabkan ada.

Dengan menyimak pesan suci di atas, maka intinya dapat dijadikan pedoman dalam kehidupan berkeluarga seperti berikut ini.

1) Dalam keluarga perlu ditanamkan perilaku suka menolong (karuna) kepada anggota keluarga yang mengalalmi duka, sedih, sakit, dalam kesengsaraan, miskin, dan sejenis dengan itu. Tidak saja kerluarga, kepada sahabat, kawan atau yang membutuhkan pertolongan juga perlu dilakukan sepanjang ada niat baik, karena hal itu adalah perbuatan mulia yang bisa mendatangkan kepuasan tersendiri dalam keluarga, jika keluarga telah mampu melakukannya. Tetapi ingat kebutuhan keluargalah adalah yang utama. Jika ada dana, pemikiran, tenaga yang dimiliki tak ada salahnya memberikan perlindungan dan perhatian kasih sayang keluarga kepada yang lainnya.

2) Terkadang hancurnya keluarga adalah adanya faktor godaan dari pihak ketiga yang masuk dalam keluarga. Bisa saja si istri tergoda laki-laki lain lebih duluan, atau sebaliknya bisa saja si suami mendapat perhatian baru dari wanita lain di luar rumah, maka hal ini bisa sebagai pemicu kehancuran keluarga. Rahasianya adalah jangan lakukan perilaku menggoda, merangsang, merayu, dan mencumbu 
lawan jenis selain istri dan suami sendiri. Jika itu dipatuhi bersama, maka yakin bahtera dalam keluarga menjadi utuh dan rukun, sepanjang faktor lainnya sudah dikendalikan bersama-sama. Ingat menggoda istri orang lain (paradara) dan menggoda suami orang lain (parapriyah) adalah sama-sama penuh dosa dan pemicu pecahkan kerukunan keluarga.

3) Antara suami dan isteri dalam keluarga dituntut berlaku arif, susila, bijaksana, waspada, penuh perhatian, dan samasama berwawasan luas dalam ilmu pengetahuan, jika hal itu sebagai landasan dalam berkeluarga, maka itu sebagai modal menuju keajegan, kelanggengan, dan kerukunan maupun umur panjang dalam membina bahtera keluarga. Tidak mungkin melakukan cerai dan pisah ranjang.

4) Satu hal yang perlu diingat terus oleh suami dan isteri, yakni tidak berkatakata yang kasar atau buruk terhadap suami atau isterinya sendiri. Ingat jika keduanya berlaku baik, pasti kebaikan pula pahala yang dinikmati berdua serta anggota keluarga.

5) Seorang suami sebagai kepala rumah tangga dan isteri sebagai pengendali ekonomi rumah tangga, hendaknya memiliki tata aturan keluarga (sopan santun) yang disepakati dan diterapkan bersama-sama dalam keluarga, tujuannya adalah untuk terciptanya kebajikan, kearifan, kebahagiaan, kerukunan, dan kesejahteraan semua anggota keluarga, tanpa kecuali. Sopan santun merupakan kendali dan pelita penerang keluarga, karena antara suami dan isteri sama-sama memiliki peran untuk menaati aturan keluarga yang telah disepakati, seperti : kesetiaan, saling mencintai, tidak menyakiti, berlaku riang dan mesra, membagi rejeki secara adil, dan sebagainya.

Dengan rambu-rambu dari pustaka suci Sarasamuscaya tersebut di atas, harapannya bahwa setiap keluarga dapat terhindar dari berbagai prahara rumah tangga yang menimpanya. Satu harapan terpenting adalah terwujudnya keluarga yang bahagia, sejahtra dan rukun selalu.

\subsubsection{Kerukunan Rumah Tangga Dalam Slokantara}

Berbicara kaitannya dengan kerukunan rumah tangga bahwa dalam pustaka suci Slokantara ada dijelaskan mengenai kebenaran yang tertinggi, jadilah manusia yang setia, kejarlah kebenaran, berbuat baiklah, orang budiman tak usah takut atau balas dendam, orang saleh pantang menyerah, dan sebagainya masih banyak lagi ajaran-ajaran kebaikan yang perlu dipahami dan dipedomani dalam membina kerukunan rumah tangga. Kemudian dalam sloka 52, 66, dan 80 berikut ini dapat dijadikan pedoman dalam mewujudkan keluarga yang rukun. Cermati maknanya berikut ini.

Caswaridipakecandran prabhate rawidipakah,

Trailokye dipako dharmah suputrah kuladipakah.

Kalinganya, yan ing wengi sang hyang candra sira pinaka damar, yan ring rahina sang hyang rawi pinaka damar, yang ring tri loka sang hyang dharma pinaka damar. Kuang yan ing kula, ikang anak suputra dang ning aji.

Bulan itu lampu malam. Surya itu lampu dunia di sing hari. Dharma itu ialah lampu di ketiga dunia ini. Dan putra yang baik itu cahaya keluarga. Waktu malam, bulanlah sebagai lampunya, di siang hari suryalah, di ketiga dunia ini dharmalah sebagai lampunya; dan dalam suatu keluarga itu putra yang baikitulah cahayanya. Demikian kata kitab suci (Oka, 1993:114). 
Abala tu cala swiwekatsu bhumipah,

Araksyanstan prayatnena manteri tyadedhi durat

Kalinganya, ikang stri yan hakambekaya ring lakinya, yogya tingalaknya. Mangkana teka sang prabhu yan ahala budi nira, kadyambeking rarayangwan, tinggalaknya ika dening mantri nira. Mangkana swabhawaning ratu lawan ikang stri, yan ahala pamaryadan ika, tan raksanan, lunghana rahayu. Haywa tan kalaksana ng prayatnadehana.

Perempuan yang tidak setia, raja yang sewenang-wenang yang tak dapat dinasehati lagi oleh mantri-mantrinya, patut ditinggalkan. Demikian juga seorang raja yang sewenang-wenang patut ditinggalkan oleh mantri-mantrinya. Demikian tindakan yang harus diambil terhadap raja dan perempuan. Jika perbuatan jahat, tak dapat diselamatkan lagi, waspadalah dan menghindarlah dari mereka. Demikian kata kitab suci (Oka, 1993:151).

\section{Sukhasyanantaram duhkham duhkhasyanantaram sukham, \\ Cakrawajjagatah sarwa wartate sthawarajanggamam}

Kalinganya, ikang rat ngaran ika, tan hana katamanan sukha duka, ikang sukha lawan dukha ta pakaheletan jatinya. Tan apilih unggwanya. Ring sugih tuwi, tan ucapan ikang kasihan. Tan apilih unggwanya. Huwus karuhun ikang jagat kabeh. Sahaning sthawarajanggama tan hana kaliwatan. Hetuning hana tapabrata, yoga, samadhi, punyadana, dharma amrih kedikan ing duhkha, geng ing sukha. Nimitaning sang wruh ring dharma, yan harep aweha dukha ring sama-samang tumwuh, pinerih nira litan ing duhkhanira ring janmantara muwah. Apan kramaning jagat kabeh, weweh winwewhan, ahutang anahur, apihutang ainahuran, amaltwinalat. Karana ning sang wruhanya. Anghing kinkenen anginakana budhining sama-sama tumuwuh. Haywa aweh laraning hati ning len. Ling sang hyang aji.

Kedukaan datang setelah kesukaan. Kesukaan mengikuti kedukaan. Semua makhluk mati dan hidup di dunia ini mengalami perputaran roda suka dan duka ini. Dunia ini bukan dunia jika tidak dikuasai oleh kesukaan dan kedukaan. Kesenangan dan kesedihan itu datangnya tidak pernah terpisah. Mereka memilih tempat beraksinya. Orang-orang kayapun dikujunginya, apalagi orang-orang miskin, Mereka kuasai seluruh dunia ini, baik benda mati maupun benda-benda hidup. Tidak ada yang dapat lepas dari kekuasaan ini. Itulah sebabnya dilaksanakannya tapa, brata (puasa), yoga, pengheningan cipta, dana sedekah dan dijalankannya dharma, karena ingin mendapatkan kesenangan sebanyakbanyaknya. Inilah sebabnya mengapa orang yang mengetahui dharma tidak mau menyakiti sesama hidupnya. Tiap orang tahu dan bertujuan untuk mempersedikit kedukaan yang akan diterimanya dalam kelahiran yang akan datang karena sudah menjadi hukum alam bahwa apa yang kita berikan sedemikian pulalah yang akan kita terima. Apa yang dipinjam itu pula yang dikembalikan, apa yang dipinjamkan itu juga yang akan diterima. Apa yang diambil dari orang lain, itu pulalah yang akan diambil darinya oleh orang lain. Inilah sebabnya mengapa orang-orang yang mengerti dharma tidak ingin untuk merampas kepunyaan orang lain karena mengetahui apa akibatnya atau ganjarannya nanti. Orang harus selalu berusaha untuk membahagiakan kawan atau sesama hidup. Janganlah sampai hati menyakiti hati orang lain. Demikianlah ajaran dari kitab suci (Oka, 1993:193-194). 
Berdasarkan beberapa kutipan sloka suci di atas, maka ada beberapa pesan suci untuk dapat dijadikan sesuluh atau pelita dalam menjalin erat bahtera rumah tangga dalam suasana hidup yang rukun, damai, dan sejahtera. Pesan dimaksud berikut ini.

1) Bagi keluarga hendaknya selalu memanfaatkan empat sesuluh utama dalam membina rumah tangga, keempat sesuluh atau pelita hidup rumah tangga, antara lain : a) surya sebagai pelita di siang hari, 2) candra sebagai pelita di malam hari, c) dharma sebagai pelita di siang hari, malam hari dan dalam keluarga, dan anak suputra atau suputri (anak yang baik) sebagai pelita dalam keluarga. Maka dari itu untuk mewujudkan keluarga yang rukun, bahagia, sejahtera, dan damai, salah satu syaratnya adalah bahwa keluarga itu agar memiliki putra dan putri yang terbaik, taat, patuh, disiplin, pintar, hormat, dan dapat menyelamatkan dan berguna bagi keluarga, bangsa dan negara tercinta.

2) Sebagai wanita, isteri, perempuan atau apapun sebutannya hendaknya selalu menciptakan kesetiaan kepada suami dalam keluarga. Demikian juga kepala keluarga, suami, atau seorang raja/ pemimpin keluarga hendaknya tidak bertindak sewenang-wenang dalam rumah tangga. Bila si isteri tidak setia dan suami bertindak sewenangwenang, maka perilaku yang dermikianitu bisa dijauhi oleh kelaurga, yanag mengakibatkan keretakan keluarga.

3) Kesukaan dan kedukaan adalah bagian hidup yang tidak bisa dipisahkan. Keduanya itu selalu dialami oleh siapapun tanpa membeda-bedakan kedudukan, status, profesi dan asal-usul keluarga itu sendiri. Suka dan duka pasti dialami oleh setiap rumah tangga. Hal itu mesti dipahami dengan baik. Namun demikian, tetaplah meyakini dan taat pada ajaran dharma (agama Hindu), sehingga dengan dharma dapat terciptanya kebahagiaan, kerukunan, dan kedamaian keluarga.

\subsubsection{Kerukunan Rumah Tangga Dalam Manawadharmasastra}

Sama halnya dengan sumber lainnya sebagaimana dipaparkan di atas, bahwa dalam pustaka suci Manawadharmasastra juga ada dijelaskan menghenai konsep kerukunan rumah tangga, yang perlu dipahami maknanya. Terkait dengan bagaimana kerukunan tersebut, ada beberapa sloka yang dikutip (Pudja dan Tjok Rai Sudharta,2002:121-124), berikut ini.

\section{Swambhawa esa narinam, Naranam iha dusanam, Atho'rthanna pramadyanti \\ Pramadasu wipaccitah.}

Pada jaman ini sudah tidak janggal seorang perempuan menggoda laki-laki, oleh karena itu orang bijaksana harus selalu waspada dalam pergaulan dengan wanita.

Yadi stri yadya warajah sreyah kimcit samacaret,

Tat sarwamacaredyukto yatra wasya ramen manah

Kalau seorang wanita atau laki-laki dari golongan yang rendah melakukan sesuatu yang membawanya kebahagiaan ia hendaknya selalu melakukannya disamping hal-hal yang diijinkan jika hatinya merasa gembira.

Sreyah eva hi dharmarthau tad darcayati, dharmarthawucyate sreyah karmarthau dharma ewa ca, artha eweha wa sreyastri iti tu sthitih

Ada yang mengatakan bahwa kebaikan yang tertinggi adalah dengan mengejar 
kebaikan rohani dan mengejar kekayaan, yang lain mengatakan memuaskan nafsu dan mengumpulkan harta benda, yang lainnya hanya dengan dharma saja, yang lainnya artha sajalah yang merupakan kebaikan yang tertinggi, tetapi yang sebenarnya kebahagiaan adalah pada keseimbangan ketiga yang tadi.

\section{Acaryasca pita saiva mata bhrata ca purwajah,}

Nartenapya waman tawya brahmanena wisesatah.

Guru, ayah, ibu dan kakak tidak boleh diperlakukan dengan tidak hormat, teristimewa bagi orang brahmana, walaupun hatinya disakiti oleh mereka.

Bila dicamkan dengan baik bait-bait dalam sloka tersebut di atas, maka betapa mulianya dan mantapnya kehidupan dan kerukunan rumah tangga itu sendiri. Mengapa demikian? Oleh karena dalam membina rumah tangga yang rukun telah diberikan rambu-rambu yang utama untuk menuju kestabuilan keluarga. Ada beberapa pesan penting sebagai pedoman dalam membina kerukunan rumah tangga, antara lain berikut ini.

1) Dalam kehidupan berumah tangga, tidak dibenarkan saling menyalahkan antara si isteri dengan si suami. Keduanya hendaknya berlaku arif dan bijaksana. Bila terjadi prahara rumah tangga, tidak semata isteri saja yang disalahkan sebagai penyebabnya, walaupun ada kesan umum bahwa si wanita acapkali dicap sebagai penggoda laki-laki, sebaliknya si suamipun juga tetap interospeksi, bahwa kelalaian yang pernah diperbuat agar tidak sampai mengorbankan isteri dan anak sendiri.

2) Bagaimanapun sederhananya wanita dan laki-laki dari segi penampilan ataupun yang lainnya, yang utama adalah bagaimana antara keduanya itu bisa menciptakan kebahagiaan bersama dalam keluarga. Apa lagi dalam keluarga itu dari turunan orang mulia, bangsawan, terhormat, maka yang demikian patut dijadikan teladan dalam hal kerukunan keluarga.

3) Antara suami dan isteri hendaknya bersama-sama menciptakan kebaikan dan kerukunan yang termulia, baik yang bersifat kerohanian, dalam mencari kekayaan, dalam kepuasan nafsu, serta dalam menunaikan kewajiban keluarga berlandaskan atas kebenaran (dharma), kesemuanya itu merupakan sumber kerukunan rumah tangga.

4) Yang patut diingat dan dilakukan dalam rumah tangga bahwa guru keluarga seperti ayah dan ibu serta orang yang dituakan dalam keluarga, hendaknya diperlakukan dengan sangat hormat, terutama oleh para penerus keluarga serta semua anggota keluarga.

Demikian pesan suci tentang kerukunan dalam pustaka suci Manawadharmasastra yang harapannya dapat dijadikan tuntunan bagi para sedharma dalam membina rumah tangga.

\subsection{Komponen Rumah Tangga Menuju Keharmonisan Masyarakat Hindu}

Suatu rumah tangga paling tidak terdiri atas seorang ayah, ibu, anak-anak, orang tua maupun mertua, saudara-saudara maupun para ipar, serta yang lainnya, yang memiliki satu ikatan rumah tangga serta keturunan sedarah. Siapapun anggota keluargaitu yang masih dalam ikatan keluarga dan rumah tangga, maka semuanya tersebut wajib menciptakan kerukunan.

\subsubsection{Suami Sebagai Ayah atau Kepala Rumah Tangga}

Dalam Manawadharmasastra bab kedua (dwityo 'adhyayah) sloka 231 (Pudja dan 
Tjok Rai Sudharta,2002:125) dinyatakan tentang ayah sebagai api keluarga berikut ini,

Pita wai garhapatyo 'gnir matagnirdaksinah smrtah,

Gurur ahawaniyastu sagni treta garoyasi

Sang Ayah disebutkan sebagai api grihapatya, ibu sebagai api daksina dan guru sebagai api ahawanya; ketiga api inilah yang paling mulia.

Ada tiga anggota keluarga yang wajib dihormati dan dimuliakan dalam keluarga, agar kehidupan rumah tangga menjadi rukun. Pertama, ayah (pita) sebagai suami sekaligus sebagai kepala rumah tangga yang dinamai sebagai api rumah tangga untuk menerangi kehidupan rumah tangga (grihapatya), kedua, ibu (mata) sebagai isteri sekaligus sebagai pengatur ekonomi keluarga yang dinamai upah/ honor/rejeki keluarga (daksina), dan ketiga, sesepuh atau pengelingsir keluarga sebagai penasihat keluarga (guru wrddha), yang mana ketiganya itu wajib dimuliakan dan dihormati oleh para anggota keluarga.

Rtu kalabhigamisyat, swadaraniratah sada,

Parwawarjam wrajeccainam, tad wrato rati kamyaya.

Hendaknya suami menggauli istrinya dalam waktu-waktu tertentu dan merasa selalu puas dengan istrinya seorang, ia juga boleh dengan maksud menyenangkan hari istrinya mendekatinya untuk mengadakan hubungan kelamin pada hari apa saja kecuali prawani (Pudja dan Tjok Rai Sudharta,2002:144).

Sebagi wujud cinta kasih dan sayang si suami terhadap sang isteri, dan demi terpenuhinya kebutuhan biologis antara suami dan isteri, maka sebagai wujud cinta kasih itu adalah adanya hubungan intim sesuai waktunya atau sesuai kebutuhan di antara suami dan isteri itu sendiri. Hal ini juga sebagai media mempererat tali kasih sayang serta merekatkan kerukunan suami isteri serta kerukunan dalam keluarga. Perlu diingat, ada perkecualian yakni setiap purwani yaitu setiap penanggal dan pangelong ping pat belas (pada hari keempat belas sebelum purnama dan tilem pada setiap bulannya) diusahakan untuk tidak melakukan hubungan intim, itu merupakan pesan suci yang wajib ditaati bersama.

\subsubsection{Istri Sebagai Ibu atau Pengatur Ekonomi Keluarga}

Dalam sloka 233 pustaka Manawadharmasastra (Pudja dan Tjok Rai Sudharta, 2002:125), ditegaskan mengenai ibu sebagi sumber kebahagiaan keluarga serta sebagai istri yang utama seperti kutipan berikut ini.

Imam lokam matrbhaktya pitrbahktya tu madhymam,

Gurusisrusaya twewam brahmalokam samasnute

Dengan menghormati ibunya ia mencapai kebahagiaan di bumi ini, dengan menghormati ayahnya ia menikmati dunia tengah tetapi dengan ketaatan terhadap gurunya ia mencapai alam Brahma.

Striyo ratnanyatho widya dharmah saucam subhasitam,

Wiwidhani ca silpani samadeyani sarwatah.

Istri-istri utama, pengetahuan tentang dharma, aturan-aturan kesucian, nasihatnasihat yang baik dan bermacam-macam bentuk kesenian boleh diterima dari siapapun juga.

Jadi si ibu adalah sebagai sumber kebahagiaan keluarga, karena si ibu telah melahirkan putra-putrinya, membesarkannya, memberikan kasih sayang kepada anaknya dan suaminya. Dimana si ibu dihormati maka dalam keluarga itu menjadi tentram, bahagia, dan rukun. Tuhan memberikan cahaya kemuliaan kepada semua anggota keluarga. Selain itu, 
bahwa si ibu selain sebagi pengendali ekonomi rumah tangga, juga sebagai istri karier, istri profesional dalam keluarga dan di tempat tugasnya. Wajarlah si istri yang demikian dihormati dan dimuliakan karena posisinya sebagai isteri yang utama atau isteri sejati.

Samtusto bharyaya bharta, bhartra tathaiwa ca,

Yasminewa kule nitya kalyanam tatra wai dhruwam.

Pada keluarga dimana suami berbahagia dengan istrinya dan demikian pula sang istri terhadap suaminya, kebahagiaan pasti kekal.

Striya tu rocamanayam sarwam tadrocate kulam,

Tasyam twarocamanayam, sarwamewa na rocate.

Jika sang istri selalu berwajah berseri-seri seluruh rumah akan kelihatan bercahaya, tetapi jika ia tidak berwajah demikian semuanya akan kelihatan suram (Pudja dan Tjok Rai Sudharta,2002:148).

Ada dua pesan yang dapat dijadikan tununan dalam mewujudkan kerukunan keluarga, yakni : pertama, keluarga menjadi bahagia dan rukun secara kekal, bila suami bahagia dengan seorang istrinya, sebaliknya si istri juga bahagia denga seorang suaminya, kedua, keluarga menjadi cerah, bahagia, dan ruku bila si istri menampakkan wajah yang berseri-seri, memberikan daya tarik yang prima (cantik secara wajar) bagi si suami setiap saat. Jadi si istri berpenampilan cantik hanya untuk suaminya saja, bukan untuk menarik perhatian yang lainnya, jika itu dipegang teguh yakinlah keluarga menjadi rukun, asalkan si suami juga memberdayakan kecantikan istrinya, bukan sebaliknya pengabdian istri disia-siakan lalu mencari yang lebih cantik lagi, mana bisa keluarga menjadi rukun, mustahil sekali.

\subsubsection{Anak Sebagai Penerus Keluarga}

Dalam keluarga bahwa anak atau putraputri sebagai buah cinta antara ayah dan ibu. Anak sebagai penerus bagi ayah dan ibunya dalam keluarga. Bila keluarga tanpa kehadiran anak, diyakini kondisi keluarga itu menjadi tidak stabil atau kurang rukun, karena anak sebagai cita-cita suci juga dalam keluarga. Dalam Manawadharmasastra ada dinyatakan mengenai bagaimana kewajiban anak terhadap orang tuanya yakni ayah dan ibunya (Pudja dan Tjok Rai Sudharta,2002:125), seperti kutipan berikut ini.

Yam matapitarrau klesam sahete sambhawenrnam,

Na tasya niskrtih sakya kartum waisasatairapi.

Kesulitan dan kesakitan yang dialami oleh orang tua pada waktu melahirkan anaknya tidak dapat dibayar walaupun dalam seratus tahun

Tayornityam priyam kuryad acaryasya ca sarwada,

Teswewa trisu tustesu tapah sarwam samapyate

Seorang anak harus selalu melakukan apa yang disetujui oleh kedua orang tuanya dan apa yang menyenangkan gurunya; kalau ketiga orang itu senang ia mendapatkan segala pahala dari tapa bratanya.

Ada dua tugas mulia yang wajib ditunaikan oleh anak dalam keluarga terhadap orang tuanya, antara lain : pertama, anak selalu berbakti kepada kedua orang tuanya, karena telah melahirkan dan membesarkannya dengan penuh kasih sayang. Diusahakan sedapat mungkin untuk melanggar perintah dan petunjuk orang tuanya (alpaka guru rupaka), kedua, si anak hendaknya dapat menaati, mematuhi, serta menghormati segala petuah, nasihat, serta petunjuk ayah dan ibunya, karena orang tuanyalah sebagai petunjuk jalan menuju 
kebahagiaan dan kesuksesan si anak dalam meniti masa depannya.

\subsubsection{Mertua dan Orang Tua Sebagai Penasihat Keluarga}

Kendali utama dalam keluarga juga ada di tangan orang tua, mertua ataupun kepala keluarga. Bagaimana peran dari padi mertua/ orang tua yang juga merangkap sebagai kepala rumah tangga, maka bisa disimak kutipan berikut ini.

Panca suna grhasthasya culli pesanyu paskarah,

Kandani codakumbhasca badh yate yastu wahayan.

Seorang kepala keluarga mempunyai lima macam tempat penyembelihan yaitu tempat masak, batu pengasah, sapu, lesung dan alunya, tempayan tempat air dengan pemakaian mana ia diikat oleh belenggu dosa (Pudja dan Tjok Rai Sudharta, 2002:150).

Sebagai orang tua atau mertua memiliki peran ganda, selain sebagai kepala rumah tangga juga sebagai penasihat keluarga atau pengarah keluarga. Dalam pesan suci di atas bahwa ada beberapa petuah suci yang wajib ditularkan dan dinasihatkan terus kepada anggota keluarga dalam rumah tangga. Pesan dimaksud, bahwa setiap anggota keluarga agar tidak melupakan lima tempat suci dalam keluarga yang wajib disucikan, yang tujuannya adalah untuk mendapatkan sumber kehidupan keluarga yang utama dan terbebas dari kekeliruan dan ketidakharmonisan keluarga, yakni : 1) tempat masak (paon), 2) batu pengasah (pengintukan basa), 3) sapu sebagai alat membersihkan sekitar rumah (sampat), 4) tempat menumbuk padi (lesung teken lu), dan 5) tempat air minum atau tempayan (jun atau gebeh yeh). Pada tempat-tempat suci itulah patut selalu diingat setiap hari dijaga kesuciannya dengan menghaturkan saiban atau banten jotan. Nasihat lain yang berguna masih perlu ditularkan terus oleh mertua atau kepala keluarga itu sendiri.

\subsubsection{Ipar Sebagai Penyeimbang Keluarga}

Bagaimana peran ipar dalam keluarga?

Tentunya ipar itu juga turut menentukan bahwa keutuhan dan kerukunan keluarga andilnya adalah sangat besar. Ipar turut menciptakan kondisi rumah tangga yang utuh. Tidak lantas seorang ipar bisa berbuat atau beraku sekehendak hati. Misalnya cerewet, manja, pemalas, suka mencampuri yang tidak pantas dicampuri, serta hal lainnya yang emnimbulkan keretakan rumah tangga.

\section{Pitrbhir bhratrbhis caitah patibhir} dewaraistatha,

Pujya bhusayita wyasca bahu kalyanmipsubhih.

Wanita harus dihormati dan disayangi oleh ayah-ayahnya, kakak-kakaknya, suami dan ipar-iparnya yang menghendaki kesejahteraan sendiri (Pudja dan Tjok Rai Sudharta,2002:147).

Dari kutipan tersebut dapat disimak maknanya bahwa ipar juga memiliki andil penting dalam mewujudkan kerukunan rumah tangga. Bukan saja si suami, ayah, anak, mertua, tetapi ipar juga sangat menentukan bagaimana kerukunan itu sebagai kebutuhan dari semua anggota keluarga. Dalam hal ini, bahwa ipar perlu memiliki tata krama atau sopan santun, terutama berlaku hormat, menghargai serta toleransi yang baik terhadap wanita yang berposisi sebagai istri, juga kepada laki-laki yang telah berstatus sebagai suami, dan yang lainnya. Itu artinya bahwa ipar diharapkan bisa menempatkan diri dengan baik dalam rumah tangga. Jangan lantas seorang ipar sebagai pemicu keretakan dan kehancuran keluarga. Atau misalnya salah satu di antara suami atau isteri yang tidak senang dengan kehadiran ipar dalam rumah tangganya, lantas ia membuatbuat dalih untuk menyalahkan iparnya, padahal iparnya biasa-biasa saja. Hal itu semestinya 
tidak terjadi, oleh karena perilaku demikian juga akan menimbulkan kondisi keluarga tidak harmonis.

\section{SIMPULAN}

Keluarga atau rumah tangga yang bahagia, tenteram, sejahtera, rukun dan damai merupakan dambaan atau cita-cita setiap insan manusia di dunia. Juga merupakan harapan utama bagi keluarga Hindu dimanapun mereka berada. Bila kehidupan rumah tangga itu menjadi rukun, maka hal itu sebagai modal utama untuk terwujudnya masyarakat yang adil dan makmur juga bisa diwujudnya (santa jagadhita) berdasarkan atas ajaran agama Hindu (dharma) serta atas dasar aturan dalam kehidupan bermasyarakat, berbangsa, dan bernegara.

Ajaran tentang kerukunan dalam rumah tangga telah diajarkan oleh ajaran suci agama Hindu. Agama Hindu memiliki sumber ajaran suci seperti : Weda, Sarasamuscaya, Bhagawadgita, Manawadharmasastra, Slokantara, dan sebagainya yang sarat dengan ajaran tentang kerukunan, baik dalam keluarga, kemasyarakatan, dan kenegaraan. Semua sumber ajaran suci tersebut hendaknya dapat dijadikan penuntun menuju bahtera keluiarga yang rukun dan damai. Kehidupan berumahtangga dengan semua anggotanya yakni suami, isteri, mertua atau orang tua, anak, ipar, saudara dan sebagainya, hendaknya secara bersama-sama setiap saat untuk menciptakan suasana rukun, damai, bahagia dalam keluarga. Semuanya memiliki peran yang sama dalam menciptakan suasana kerluarga yang harmonis.

\section{DAFTAR PUSTAKA}

Kadjeng, I Njoman, dkk. 2000. Sarasamuscaya. Pemda Bali Denpasar.

Maswinara, I Wayan, 1997. Bhagawadgita Dalam Bahasa Inggris dan Indonesia. Surabaya:Paramita.

Maswinara, I Wayan, 1998. Sistem Filsafat Hindu (Sarva Darsana Samgraha). Surabaya:Paramita.

Oka, I Gusti Agung, 1993. Slokantara. Jakarta:Hanuman Sakti.

Pudja, G. 2004. Bhagawadgita. Surabaya: Paramita.

Tim Penyusun, 1994. Kamus Besar Bahasa Indonesia. Jakarta:Depdiknas, Balai Pustaka.

Tim Penyusun, 2005. Kamus Istilah Agama Hindu. Pemda Bali Denpasar.

Titib, I Made, 1996. Veda Sabda Suci Pedoman Praktis Kehidupan. Surabaya: Paramita.

Sivananda, Sri Svami, 1993. Intisari Ajaran Agama Hindu. Surabaya: Paramita. 